\title{
Consortium plans 'public' map of genome
}

London. Last week's meeting in Washington to discuss strategies for compiling a transcript map of the human genome - a physical guide to the possible location of almost 100,000 human genes - agreed to co-ordinate efforts by an informal consortium of major research institutions from the United States, Britain and France to push the project forward (see Nature 371, 365; 1994).

Such a map is destined to become a basic research tool for the pharmaceutical industry in the next century. But members of the consortium, which is being organized under the umbrella of the Human Genome Organization (HUGO), are insisting that the results of their endeavours should be placed freely in the public domain.

At the Washington meeting, organized by Britain's Wellcome Trust, it was in particular agreed that all members must accept that the use of the transcript map by scientists from both the public and private sector should be "unencumbered" - that is free of any legal or commercial constraints.

One of the key participants in this consortium will be a research group carrying out a sequencing project at the Washington University in St Louis, Missouri, with support from the US pharmaceutical company Merck Sharp \& Dohme.

Two weeks ago, Merck announced that, in a direct challenge to the conditions being required by Human Genome Sciences Inc. (HGS) on access to cDNA sequence data compiled by its Institute of Genomic Research (TIGR), headed by Craig Venter, the results of its own project would be made freely available to the scientific community with no conditions attached (see Nature 371, 463; 1994).

During last week's meeting, Merck's decision to back a 'public' sequencing exercise was enthusiastically endorsed by various scientists from academic institutions. Many expressed their concern over the terms of access to the TIGR sequence data being demanded by HGS and its chief sponsor, the pharmaceutical company SmithKline Beecham (see Nature 371, 365; 1994).

One participant, for example, said he had been told that no scientists would be allowed access to more than 100 partial sequences a year - equivalent to less than one per cent of the total database.

But Merck, which has endeavoured to stake out the moral high ground in the current dispute of public versus private 'ownership' of the human genome, also received the backing of several other pharmaceutical companies represented at the meeting.

Such companies claim to be worried that a small group of genome companies could corner the market in genome information and thus potentially hold to ransom any other commercial enterprise seeking to use this information. "We feel that, although patents may be granted on products containing [genetic] information, they should not be allowed on the information itself," says Barry Ross, research director of Glaxo. "My impression is that many other companies have the same feeling."

In response, representatives of HGS at the meeting are said to have used the occasion to defend their position vigorously, pointing out that several academic institutions, including the Howard Hughes Medical Institute, have already accepted the terms on which it is offering scientists access to TIGR's data.

William Haseltine, president of HGS, pointed out that TIGR has already sequenced more than 150,000 partial gene sequences, soon to be made accessible through its $\mathrm{Hu}$ man cDNA Databank. TIGR's activities had

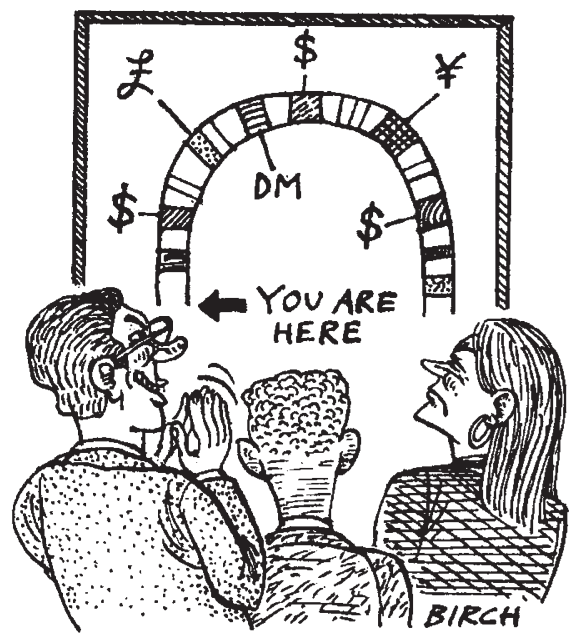

already proved of immense potential value to the pharmaceutical and diagnostics industry, he said, adding that it was reasonable for those who had backed the project to be looking for a return on their investment.

Haseltine was supported in his defence of HGS's strategy by at least one other genesequencing company, Incyte of Palo Alto, California, which claims that it has already sequenced almost 30 per cent of the genome, and has entered into an agreement with at least one major pharmaceutical company (Pfizer Inc.) for access to its database.

Randy Scott, chief executive officer of Incyte, said that his company was in a position where, if funds were forthcoming, it could map "half of the genome" by the end of next year - providing that investors in such a project see the likelihood of a return on their money.

He also criticized the strategy of 'open access' advocated by Merck as potentially undermining the ability of information-based companies such as Incyte to help in the swift discovery of new genes through their sequencing efforts. "Merck's strategy could prevent anyone getting a patent on a complete sequence," Scott warns.
Despite the differences of opinion, it was agreed at the end of the meeting that members of the consortium, which are likely to include the Sanger Centre in Britain, the Whitehead Institute in Boston, and researchers at the University of Washington and Stanford University, would work towards pooling their efforts on a communal transcript map over the next 18 months.

A further meeting of the main participants will be held under the auspices of HUGO - probably in the United Kingdom - within the near future. This will discuss progress on efforts aimed, for example, at ensuring that participating institutions achieve common standards of quality.

Francis Collins, the head of the National Institutes of Health's (NIH's) Human Genome Programme, is reported to have expressed strong opposition during the Washington meeting to any private participation in building the transcript map which would (like the use of TIGR's cDNAs) involve constraints on the use of its data.

Collins has so far refused to comment further on NIH's plans. But it is expected that Harold Varmus, the director of NIH, will support his suggestion that the NIH should support work that is part of an international effort whose results are placed unencumbered in the public domain.

At the same time, a number of pharmaceutical companies - including the US company Pfizer and the UK-based Glaxo and Zeneca, all of which were represented at the Washington meeting -- are also reported to be considering how, in support of Merck's strategy, they too could provide funds for a public-domain mapping project. "We would be prepared to support such an activity involving a partnership of industry and academic groups to map and sequence cDNAs," says Ross of Glaxo.

HGS has already indicated that it is holding discussions with other research groups on how a mapping project using the TIGR sequences might be carried out using private finance. But it will still be allowed to attend the next meeting of the 'public domain' consortium -- even though it (in common with several other groups) is not at present prepared to accept the conditions required of full consortium members.

Michael Morgan of the Wellcome Trust says that part of the success of the heavily attended Washington meeting was the open dialogue it permitted between advocates of the conflicting approaches. But he remains adamant that the trust has little interest in backing efforts to map the genome with commercial strings on access to the resultant data. "The Wellcome Trust does not have a remit to protect industry," says Morgan, although adding that "at the same time, we have no wish to undermine it."

David Dickson 